\title{
Proposal of a Mechanism for Car Seat Movement
}

\author{
Vladimír Pavelčík ${ }^{1 *}$, Dalibor Barta', Milan Sapieta ${ }^{1}$ \\ 1 University of Žilina, Faculty of Mechanical Engineering, Univerzitna 1, 010 26, Žilina, Slovak Republic \\ * Corresponding author's e-mail: vpavelcik234@gmail.com
}

\begin{abstract}
This article is focused on the height adjustment of a front car seat. The goal was to design seat movement in pure vertical direction. The article begins with a theoretical introduction, in which the functions and parts of car seats were described. The next part contains possible schematic designs of a mechanism, as well as the reasons for possible changes of the contemporary mechanisms. Afterwards, some functional parameters of the chosen schematically-designed mechanism were calculated, the results could then be used for further calculations needed for the creation of a three-dimensional model of the mechanism. The article deals mainly with the theoretical principles, and there are many further possibilities for development within the subject.
\end{abstract}

Keywords: car seat, height adjustment, design of kinematics, schematic design.

\section{INTRODUCTION}

Nowadays, it is almost impossible to imagine a means of transport aimed at transporting people without seats. Automobiles are not an exception. People are different from numerous points of view, taking into account their statures, or preferences of positions they consider comfortable. Regarding the impossibility to manufacture a seat adjusted to everybody, a principle of seat adjustment according to the needs of a seated person is being used. Various seat adjustment mechanisms are used. Seats can be divided into more categories according to the number of their mechanisms and origin of power for modifying their position. The division reflects also price of a vehicle; consequently, low- and middle-class-vehicles contain seats with fewer mechanisms, while more luxurious vehicles have seats which are adjusted in a more complex way. As in other industrial areas, the automotive industry involves innovations as essential part of evolution, including the adjustment mechanisms of car seats. The task of the article was to attempt one of such innovations - to design a principle of operation of a mechanism reflecting an innovative approach to seat adjustment.

\section{FUNCTIONS AND PARTS OF A CAR SEAT}

Because people differ from each other in their body-sizes, shapes, weight, etc., and this difference is worldwide territorial, a seat has to hold a person sitting in the correct position, due to the safety and health protection reasons (correct positioning of the back, shoulders, hips, legs, supporting correct angles between different parts of the body, etc.). An incorrect position of the seat also influences concentration and level of tiredness of the driver and other psychological aspects of safety in the road transportation $[9,11]$. Another important function is to give the driver the best possible view on the road in front of the car as well as rear-view mirrors.

A cushion and a central part of a seat back are used to hold the passenger in a correct position, as well as provide him with the basic comfort and protection. Side cushions protect the passenger from unwanted motion caused by the centrifugal force in road curves. They also contribute by their part to the comfort. A side cushion might contain an air-bag. After an accident, when the air-bag deployed, it is highly recommended to replace the whole seat. 
A headrest is one of the most important passive safety elements. Equally to the cushion and backrest, it can be adjustable (in this case it is a separate part of a car seat and it can be removed with no difficulties) or it may not be adjustable, and then it is not removable. In contrast, an armrest, which is not in the figure, is only an element of comfort. Moreover, it does not necessarily have to be a part of the seat, it can constitute a part of the central console. There are many more possible elements to be added, for example a seat belt mechanism, parts of seat adjustment mechanisms, a trim-based pocket, where small things can be stored by a rear-seat passenger, etc.

From the inner point of view, parts of a car seat can be divided into:

- metal parts,

- plastic parts,

- foam parts,

- trims,

- other parts.

The group of metal parts consists of:

- basic frame,

- mechanisms,

- dampening elements,

- others.

The basic frame means various welded sheets, which hold the passenger in the correct position, which is essential from the medical point of view, and secure the proper shape of the seat. The metal mechanisms are the parts used to adjust the basic frame to the required position by moving and rotating the sheets of the frame. According to the number of possible movements, car seats are divided to: 2-way, 4-way, 6-way and more-way. The possible movements of a six-way car seat are presented in Figure 2.

Plastic parts mostly correspond to different coverings. Some functional elements, such as the lever of the height adjustment mechanism, can be also made of plastic materials. A plastic table for a rear seat passenger may sometimes be attached on the back side of the some row seats. Otherthan-fixed connections between metal parts are usually made of plastic to avoid noise contamination when adjusting a seat to the correct position [14]. Foam parts are considered to be a very important comfort element. They are usually made of polyurethane, in which some additives can be inserted and are mostly connected with the metal dampening elements [7]. The foam can be found in the cushion, backrest and headrest. Trims are the most important part for the first impression of a customer, who see them, touch them, and who should feel comfortable with them. Their material can be very variable - leather, textile, plastic fibres etc [1].

\section{DEFINED POINTS OF A CAR SEAT}

The development of a new car seat begins after receving the order from a customer. The customer specifies (not only) positions of various points and fields, which the developer has to take

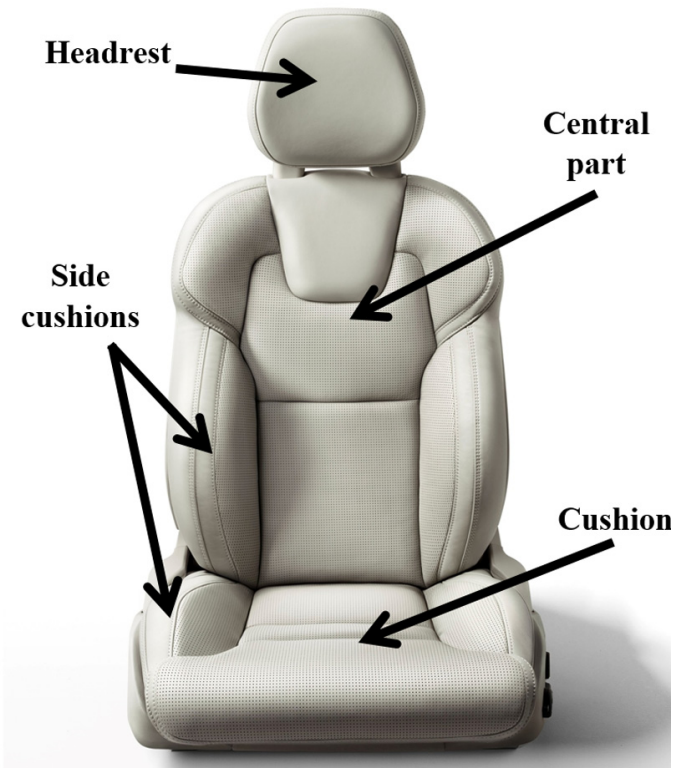

Fig. 1. Parts of a front-row car seat

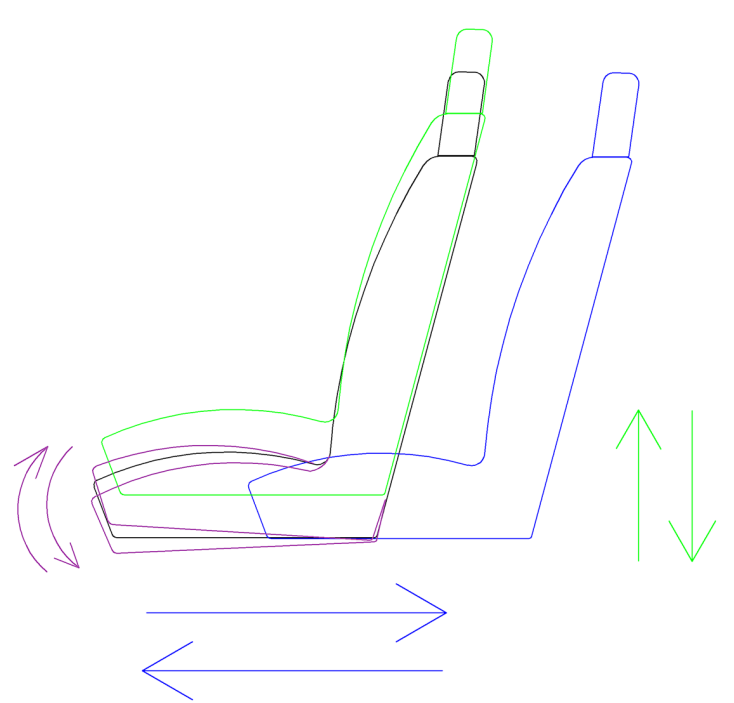

Fig. 2. An example of possible movements of a 6-way front-row car seat 
into the account. These points mostly have to secure the person's safety and also ensure that the car is being driven safely by the driver. During crash-tests of a vehicle, the risk is too high to let any person sit on the seat, so dummies are usually used instead. Only some of the points and fields are mentioned here, because the number of them is fairly high. For example, the field of points representing the driver's view, which creates an eye-ellipse securing good view not only out of the vehicle, but in the interior of the vehicle as well, which is important from the safety point of view. A point, which represents the centre of rotation of the head (cervical vertebrae); Heel point, which represents the contact of the driver's heel with the floor of the vehicle; and perpendicular projection of the axis of rotation of the thighs to the torso of the body to the xz plane, which is called H-point (Hip - point), sometimes reffered to as SRP - Seat reference point. The set of all $\mathrm{H}$-points available on a car seat is called H-point field (Fig. 3).

The whole innovation process starts with a reasoning about the height adjustment. Statistics state that the tallest people set their seat to the position B (Fig. 3), because of their need to have sufficient space for their legs as well as for their heads. In contrast, the shortest people would, generally, use the position D in the picture (Fig. 3). Short people usually have shorter legs, but they still need to remain in contact with pedals. Additionally, short people still need to see the road above the steering wheel. An average person would adjust the seat somewhere in between those positions, but points $\mathrm{A}$ and $\mathrm{C}$ stay unused. The task is to design $\mathrm{H}$-point field, which would remove the points $\mathrm{A}$ and $\mathrm{C}$ and widen the $\mathrm{H}$-point field in the area near points B and D. One

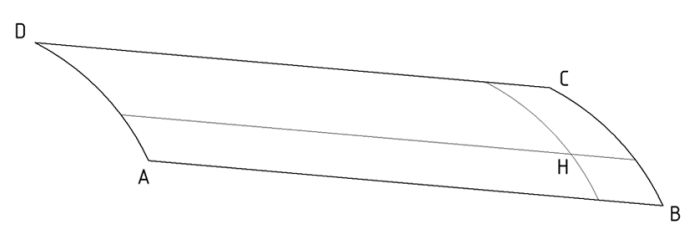

Fig. 3. H-point field

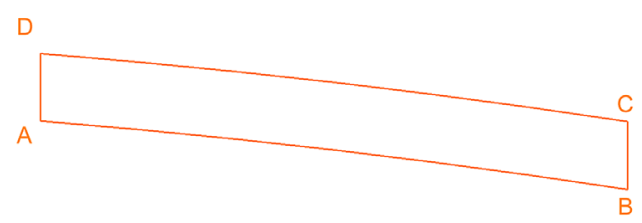

Fig. 4. Innovated H-point field possible innovative H-point field taking into account the conditions mentioned above is presented in Figure 4.

It is wise to design a mechanism (at least schematically), which is able to provide such an $\mathrm{H}$-point field. On the basis of Figure 4, the handpowered lift shall lie in a purely vertical direction. For the purposes of this innovation process, at least a few variants had to be presented. According to this information, some parallels can be seen in the technical solutions all over the world. Exactly this kind of movement can be noticed in combustion engines (crank shaft - connecting rod - piston), from other examples can be mentioned, including cam mechanism, pantographic mechanism or hydraulic or pneumatic pistons performing the wanted movement $[2,3,8,5]$. The simplest way would be the hydraulic one.

Two principles of hydraulic mechanisms can be used. As a Variant A it is the hydraulic mechanism with single acting cylinders (Fig. 5), where hand-powered oil pump increases the pressure in the pistons and cause the movement up, while the manually operated valve in cooperation with person's gravity causes the movement down. Variant $B$ presents the mechanism with double acting cylinders (Fig. O), which is based on the principle of pumping the liquid from one piston to other

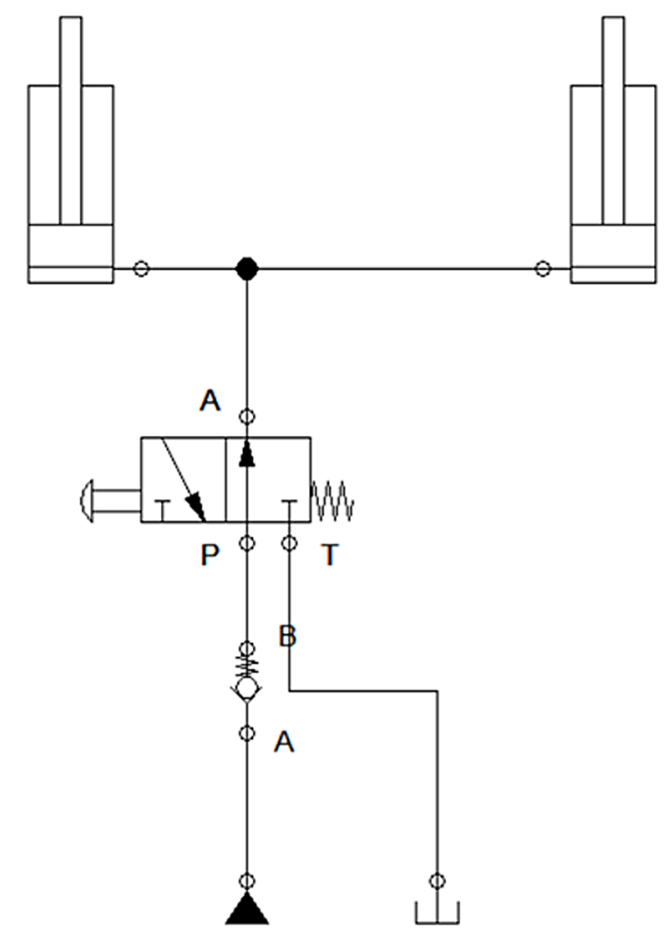

Fig. 5. Variant A - Hydraulic principle - single acting cylinders 


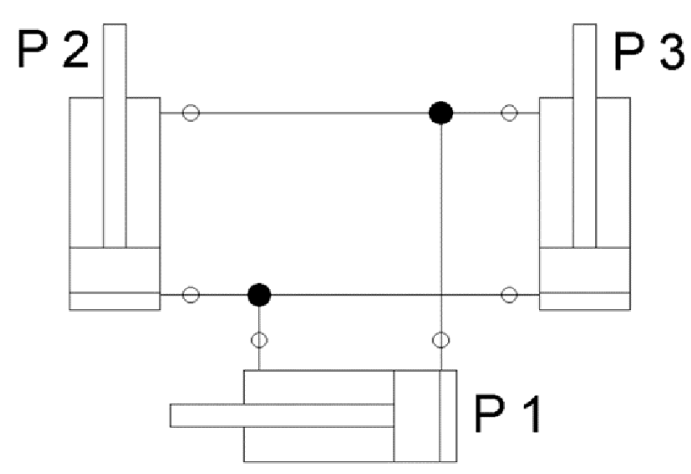

Fig. 6. Variant B - Hydraulic principle double acting cylinders - pumping

pistons (amount and dimensions of the pistons must be calculated).

The advantages of hydraulics could be low force needed to power the mechanism, exact positioning; moreover, with the use of more pistons, the dimensions decrease as well. However, there are two important disadvantages of using hydraulics. Firstly, the weight, which is caused by hydraulic liquid as well as mass of hydraulic sysem components and which is very important parameter related for example to fuel consumption and emisions, or to the braking characteristics of a vehicle $[10,6]$. Secondly, no liquid should be flowing out of any car seat in case of, for example an accident, which could not be ensured without many difficulties. As a result, the hydraulic mechanism cannot be easily used for height adjustment of a car seat.

In order to advance the proposal to the next level, a principle of crank mechanism had been selected. Unlike in the engine, the piston cannot be the part causing the movement of the whole mechanism, because the piston must be somehow connected to the person to ensure his or her lift. The first idea resulted in variant $\mathrm{C}$, which uses group of gear wheels and gear racks (Fig. 7), where the gear wheel driven through a mechanism by hand would cause the movement of the gear rack connected via binary element to both "crank shaft" and "connecting rod".

However, this solution would significantly increase the total mass of the seat, so a slightly modified mechanism can be seen on the scheme of the variant $\mathrm{D}$ at the bottom (Fig. 8). Here, the crank mechanism as well as the binary element remain, but the group of gears is replaced by one threaded rod and two moving nuts. The threaded rod must have two threaded parts and threads must be oriented oppositely. Then, the rotation of the threaded rod causes lift of the cushion via the binary element and crank mechanism.

\section{CALCULATION OF BASIC DIMENSIONS OF THE CRANK PAR=T OF THE MECHANISM}

On the basis of the variant D (Fig. 8), a scheme containing symbols (Fig. 9) is derived.

Afterwards, the following equations can be written:

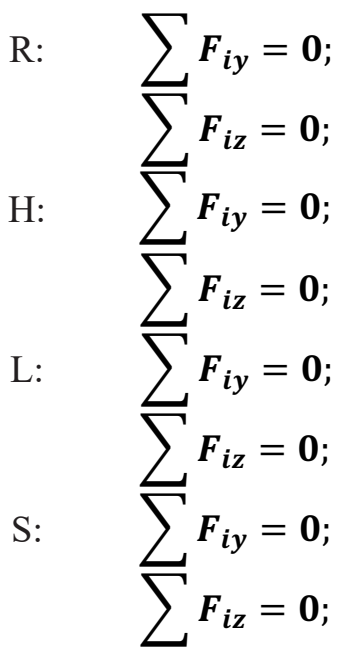

$$
\begin{aligned}
& R_{y}+N_{l} \cdot \sin (\beta)=0 \\
& -F_{g}-T-N_{l} \cdot \cos (\beta)=0 ; \\
& -N_{l} \cdot \sin (\beta)-N_{r} \cdot \sin (\alpha)+N_{q} \cdot \cos (\gamma)=0 ; \\
& N_{l} \cdot \cos (\beta)-N_{r} \cdot \cos (\alpha)-N_{q} \cdot \sin (\gamma)=0 ; \\
& L_{y}+N_{r} \cdot \sin (\alpha)=0 \\
& L_{z}+N_{r} \cdot \cos (\alpha)=0 \text {; } \\
& -N_{q} \cdot \cos (\gamma)-F_{Q}=0 \text {; } \\
& N_{q} \cdot \sin (\gamma)+S_{z}=0
\end{aligned}
$$

where $N_{\mathrm{r}}, N_{q}$ and $N_{l}[N]$ are axial forces, $R_{y}, L_{y}, L_{z}, S_{z}[N]$ are reactions of the frame,
$F_{g}, F_{Q}[\mathrm{~N}], \alpha, \beta, \gamma\left[{ }^{\circ}\right]$ are parameters given in Fig. 9. Natually, friction can influence the final result, so the friction caused by 


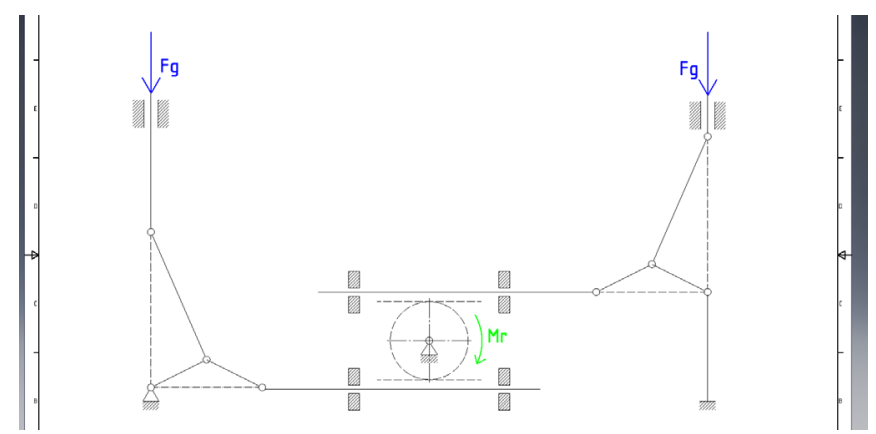

Fig. 7. Variant $\mathrm{C}$ - mechanism with gear racks and gear wheels

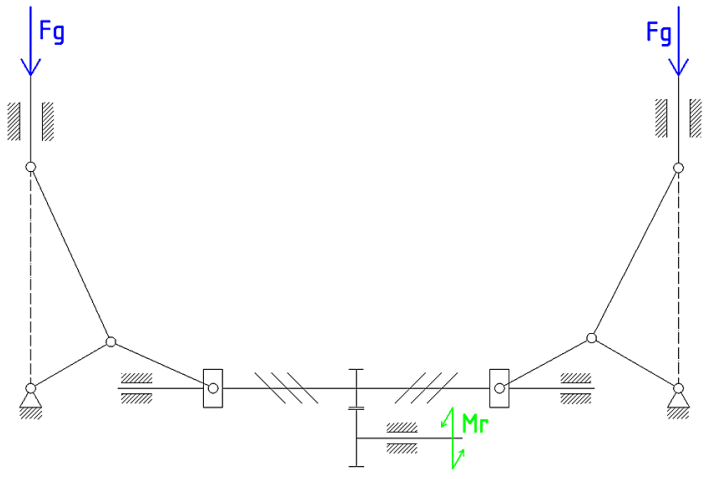

Fig. 8. Variant D - mechanism with the threaded rod

normal force $\mathrm{R}_{\mathrm{y}}$ is introduced in equation (2) as force T $[\mathrm{N}]$. This force is equal to:

$$
T=R_{y} \cdot f=-N_{l} \cdot \sin (\beta) \cdot f ;
$$

where $f[-]$ is coefficient of friction at point $R$ (Fig. 9). In order to minimize the torque needed to push the cushion up, it is essential to find the

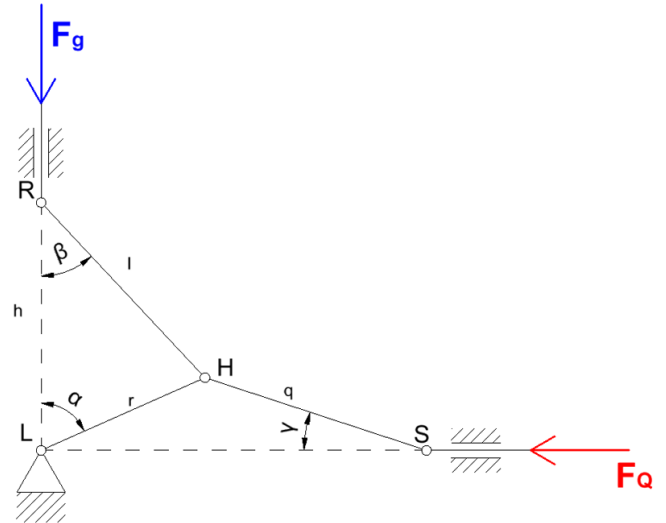

Fig. 9. Angles and lengths of the crank part of the mechanism

minimum of $\mathrm{F}_{\mathrm{Q}}$ function. Some mathematical operations are needed in a few steps to derive $F_{Q}$ as a function of lengths of parts $\mathrm{r}, 1, \mathrm{~h}, \mathrm{q}$ of the multibody system (Fig. 9). Below, only some of the steps are stated:

$$
\begin{aligned}
& -N_{l} \cdot \sin (\beta)-N_{r} \cdot \sin (\alpha)+N_{q} \cdot \cos (\gamma)=0 ; \quad /:(-\sin \alpha) \\
& N_{l} \cdot \cos (\beta)-N_{r} \cdot \cos (\alpha)-N_{q} \cdot \sin (\gamma)=0 ; \quad \text { /: }(\cos \alpha) \\
& N_{l} \cdot\left(\frac{\sin (\beta)}{\sin (\alpha)}+\frac{\cos (\beta)}{\cos (\alpha)}\right)-N_{q} \cdot\left(\frac{\cos (\gamma)}{\sin (\alpha)}+\frac{\sin (\gamma)}{\cos (\alpha)}\right)=0 \\
& N_{q}=N_{l} \cdot \frac{\frac{\sin (\beta)}{\sin (\alpha)}+\frac{\cos (\beta)}{\cos (\alpha)}}{\frac{\cos (\gamma)}{\sin (\alpha)}+\frac{\sin (\gamma)}{\cos (\alpha)}} \\
& N_{q}=\frac{-F_{g}}{\cos (\beta)-f \cdot \sin (\beta)} \cdot \frac{\frac{\sin (\beta)}{\sin (\alpha)}+\frac{\cos (\beta)}{\cos (\alpha)}}{\frac{\cos (\gamma)}{\sin (\alpha)}+\frac{\sin (\gamma)}{\cos (\alpha)}} ; \\
& F_{Q}=F_{g} \cdot \frac{\cos (\gamma)}{\cos (\beta)-f \cdot \sin (\beta)} \cdot \frac{\frac{\sin (\beta)}{\sin (\alpha)}+\frac{\cos (\beta)}{\cos (\alpha)}}{\frac{\cos (\gamma)}{\sin (\alpha)}+\frac{\sin (\gamma)}{\cos (\alpha)}}
\end{aligned}
$$




$$
F_{Q}=F_{g} \cdot \frac{\sin (\alpha+\beta) \cdot \cos (\gamma)}{\cos (\alpha-\gamma) \cdot(\cos (\beta)-f \cdot \sin (\beta))} .
$$

In order to find $\mathrm{F}_{\mathrm{Q}}$ as a function of parts dimensions, the following three cosine-rule equations must be added:

$$
\begin{gathered}
\alpha=\arccos \frac{r^{2}+h^{2}-l^{2}}{2 \cdot r \cdot h} ; \\
\beta=\arccos \frac{h^{2}+l^{2}-r^{2}}{2 \cdot l \cdot h} ; \\
\gamma=\arcsin \frac{r \cdot \sin (90-\alpha)}{q}=\arcsin \frac{r \cdot \cos (\alpha)}{q}=\arcsin \frac{h^{2}+r^{2}-l^{2}}{2 \cdot q \cdot h} ;
\end{gathered}
$$

where $r, l, h, q[\mathrm{~mm}]$ are parameters marked in the Figure 9 . The final function can be reached by a substitution of $\alpha$ (equation 10), $\beta$ (11), $\gamma$ (12) in equation (9):

$$
\begin{aligned}
& F_{Q}= \\
& =\frac{F_{g} \cdot \sin \left(\arccos \frac{r^{2}+h^{2}-l^{2}}{2 \cdot r \cdot h}+\arccos \frac{h^{2}+l^{2}-r^{2}}{2 \cdot l \cdot h}\right) \cdot \cos \left(\arcsin \frac{h^{2}+r^{2}-l^{2}}{2 \cdot q \cdot h}\right)}{\cos \left(\arccos \frac{r^{2}+h^{2}-l^{2}}{2 \cdot r \cdot h}-\arcsin \frac{h^{2}+r^{2}-l^{2}}{2 \cdot q \cdot h}\right) \cdot\left(\frac{h^{2}+l^{2}-r^{2}}{2 \cdot l \cdot h}-f \cdot \sin \left(\arccos \frac{h^{2}+l^{2}-r^{2}}{2 \cdot l \cdot h}\right)\right)} .
\end{aligned}
$$

This equation can be simplified to:

$$
\boldsymbol{F}_{Q}=\boldsymbol{F}_{\boldsymbol{g}} \cdot \boldsymbol{k}
$$

where $k$ is substitution:

$$
\begin{aligned}
& k= \\
& =\frac{\sin \left(\arccos \frac{r^{2}+h^{2}-l^{2}}{2 \cdot r \cdot h}+\arccos \frac{h^{2}+l^{2}-r^{2}}{2 \cdot l \cdot h}\right) \cdot \cos \left(\arcsin \frac{h^{2}+r^{2}-l^{2}}{2 \cdot q \cdot h}\right)}{\cos \left(\arccos \frac{r^{2}+h^{2}-l^{2}}{2 \cdot r \cdot h}-\arcsin \frac{h^{2}+r^{2}-l^{2}}{2 \cdot q \cdot h}\right)\left(\frac{h^{2}+l^{2}-r^{2}}{2 \cdot l \cdot h}-f \cdot \sin \left(\arccos \frac{h^{2}+l^{2}-r^{2}}{2 \cdot l \cdot h}\right)\right)} .
\end{aligned}
$$

The last important step is to find the minimum of this function of four variables $\mathrm{r}, \mathrm{l}, \mathrm{h}$ and $\mathrm{q}$; either by finding the minimum of the function of four variables, or by reducing this function to a lower number of variables, or by any other mathematical method $[12,13]$. Moreover, it is wise not to omit the triangle inequality, which says, that the sum of lengths of any two sides of triangle must exceed the length of the third side [4]. This rule has to be obeyed in the position up as well as in the position down of the purposed mechanism. For this reason, no further calculation can be made without stating the length of the lift for the specific car seat.

\section{SOLUTION RESULTS}

The article presents four variants of mechanisms, which could meet the requirements for kinematics of the newly-designed H-point field, which were presented schematically. From those four schemes, the one based on the crank mechanism and the threaded rod was selected for further development. Calculation of the basic dimensions was then taken into the point, where exact numbers are needed to continue with the calculation. For the specific car seat, according to the technical specification, some parameters are set to numbers. These are shown in the Table 1.

On the basis of these parameters, function $\mathrm{k}$ of four variables can be transformed to function of two variables $r$ and 1 . The function of two variables can be seen in Figure 10, where also triangle inequality is shown - parts of curves lying in the

Table 1. Parameters specified for specific car seat

\begin{tabular}{|c|c|}
\hline Parameter & Value \\
\hline Lift z & $40 \mathrm{~mm}$ \\
\hline $\mathrm{h}$ & $36 \mathrm{~mm}$ \\
\hline $\mathrm{y}$ & $8^{\circ}$ \\
\hline
\end{tabular}




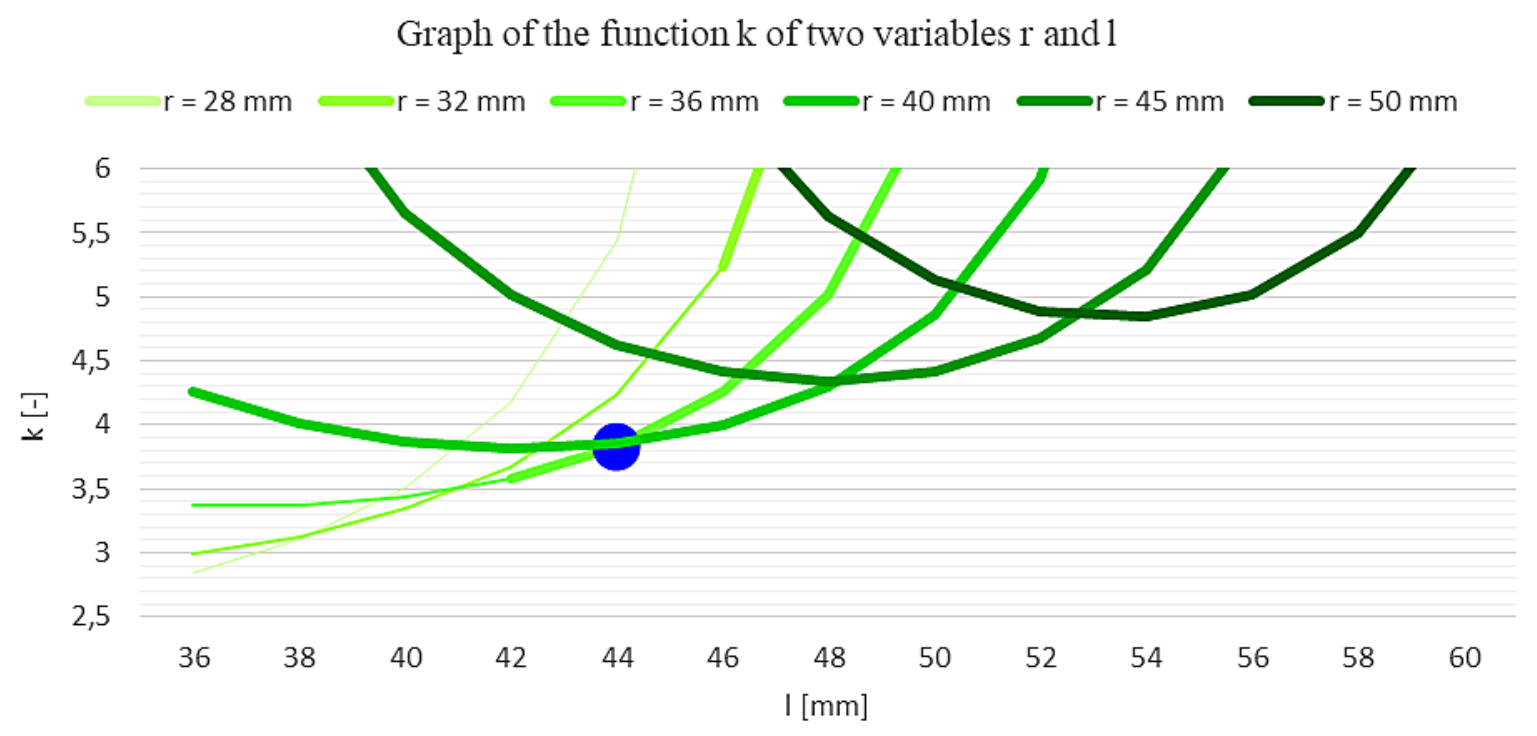

Fig. 10. Graph of the function $\mathrm{k}$ of two variables $\mathrm{r}$ and $\mathrm{l}$

area, where triangle inequality requirement is not met, are thin, whereas the parts of curves lying in the area, where all requirements are met, are thick. As a result, the lowest value of $\mathrm{k}$, which finally means the lowest value of $F_{Q}$, can be found on the line for $\mathrm{r}=36 \mathrm{~mm}$ and at point $\mathrm{l}=44 \mathrm{~mm}$. Even though there are some points for $1<44 \mathrm{~mm}$, from the practical point of view, it is better to take the first even-numbered length satisfying all other requirements, instead of an uneven-numbered one.

\section{CONCLUSION}

Four variants of the mechanism for car seat adjustement in a more complex way were presented in the article. The variant based on the crank mechanism and the threaded rod was selected as the most appropriate solution. The proposed solution suitably meets the requirements for the H-point position.

The solutions with hydraulic drive were considered as a less suitable due to the increased weight of the mechanism and the risk of hydraulic fluid leaking into the vehicle interior.

The calculation of basic dimensions of the crank part of the mechanism was presented as well. As it turned out, no further calculation can be made without stating the length of the lift for the specific car seat.

\section{Acknowledgement}

This paper was supported by following projects: KEGA 017ŽU-4/2017 and ITMS 26110230107.

\section{REFERENCES}

1. Albini G. et al. Comparative study of mechanical characteristics of recycled PET fibres for automobile seat cover application. Journal Oof Industrial Textiles, 2019, 992-1008.

2. Baran P., Kukuca P., Barta D., Labuda R., Drozdziel P., Pukalskas S. The Issue of Balancing Internal Combustion Engines with Non-Conventional Crank Mechanism. Communications - Scientific Letters of the University of Zilina. 2017. 19(2A), 36-41. Retrieved from: http://communications.uniza.sk/ index.php/communications/article/view/209.

3. Blatnicky M. Dopravné a manipulačné zariadenia, riešené príklady. Žilinská univerzita v Žiline, 2015.

4. Khamsi M. A., Kirk W. A. An Introduction to Metric Spaces and Fixed Point Theory. John Wiley \& Sons, 2001.

5. Kukuca P., Barta D., Labuda R., Gechev T., et al. Engine with unconventional crank mechanism FIK 1. MATEC Web of Conferences 2018, 244, 03004.

6. Lebedevas S., Pukalskas S. et al. Research on Fuel Efficiency and Emissions of Converted Diesel Engine with Conventional Fuel Injection System for Operation on Natural Gas. Energies 2019, 12 (12), 2413; https://doi.org/10.3390/en12122413.

7. Lee Sung-hoon et al. Effect of Copolymer Polyol Content and NCO Index on the Comfort of Polyurethane Seat Foam Pad for Automobiles. POLYMERKOREA, 2019, 401-409.

8. Nieoczym A., Caban J., Marczuk A., Brumercik F. Construction design of apple sorter. In: Contemporary research trends in agricultural engineering. Book Series: BIO Web of Conferences, 2018, Volume: 10, Article Number: UNSP 02025. 
9. Ondrus J., Karon G. Video System as a Psychological Aspect of Traffic Safety Increase. Proc. of 17th International Conference on Transport Systems Telematics (TST), Katowice, Poland 2017.

10. Ondrus J., Vrabel J. and Kolla E. The influence of the vehicle weight on the selected vehicle braking characteristics. Transport means 2018. Part I: proceedings of the international scientific conference, 384-390.

11. Peng J; Wang X.; Denninger L. Effects of Anthropometric Variables and Seat Height on Automobile Drivers' Preferred Posture With the Presence of the Clutch. Human Factors, 2018, 60(2), 172-190.

12. Sapietova A., Saga M. et al. Application of optimization algorithms for robot systems designing.
International journal of advanced robotic systems, 15(1), 2018, 1-10.

13. Zapomel J., Dekys V., Ferfecki P., Sapietova A., Saga M., Zmindak M.: Identification of Material Damping of a Carbon Composite Bar and Study of Its Effect on Attenuation of Its Transient Lateral Vibrations. In: International Journal of Applied Mechanics, 7 (6), 2015, 1-18.

14. Zvolensky P. et al. Simulation of sound transmission through the porous material, determining the parameters of acoustic absorption and sound reduction. Machine modelling and simulations 2017 [electronic]. London: Édition Diffusion Presse Sciences, 2018, 1-10. Retrieved from: https://doi. org/10.1051/matecconf/201824403004ITEP'18. 